\title{
CHANGES IN SURVIVAL RATES OF LESSER SNOW GEESE WITH AGE AND BREEDING STATUS
}

\author{
Charles M. Francis, ${ }^{1,4}$ Miriam H. Richards, ${ }^{1,5}$ \\ FRED COOKE, ${ }^{1}$ AND ROBERT F. ROCKWELL ${ }^{2,3}$ \\ ${ }^{1}$ Department of Biology, Queen's University, Kingston, Ontario K7L 3N6, Canada; \\ ${ }^{2}$ Department of Biology, City College of New York, New York, New York 10031, USA; and \\ ${ }^{3}$ Department of Ornithology, American Museum of Natural History, Central Park West, \\ New York, New York 10024, USA
}

\begin{abstract}
Survival rates of Lesser Snow Geese (Chen caerulescens caerulescens) were examined based on recoveries and recaptures of about 350,000 geese banded at breeding colonies in northern Canada, at migration stopover points in the Dakotas and Missouri, and on the wintering grounds in Louisiana and Texas. First-year survival rates for goslings banded on the breeding grounds varied from 10 to $70 \%$ of adult survival rates. Much of the juvenile mortality occurred on the breeding grounds or early on the first migration. Young geese that reached migration stopovers or the wintering grounds were more vulnerable to hunters than adults, but had only slightly lower survival rates than adults. Greater vulnerability and lower survival continued through the second year of life, even though yearlings do not breed. In contrast, older birds that did not breed, or failed early in a nesting attempt, were much less vulnerable to hunters in the following hunting season than successful breeding adults, but did not appear to have higher survival as a result. Geese captured for the first time as breeding adults had slightly lower survival rates than geese that had been recaptured at the colony at least once, suggesting experienced breeders have higher survival. Although there was some evidence that older birds were slightly more vulnerable to hunters, there were no signs of any changes in survival rate with age in older geese, indicating that senescence, if it affects survival, does not do so for at least the first 10 to 15 years of age. With current hunting levels, less than $5 \%$ of Lesser Snow Geese are likely to live beyond this age. Our study demonstrates a variety of statistical methods for testing hypotheses about age-specific survival using both recovery and recapture data, even when the data do not permit estimation of the exact survival rates. Received 13 May 1991, accepted 13 January 1992.
\end{abstract}

AN IMPORTANT component of fitness for any organism is its probability of survival from one year to the next. This probability may vary among individuals due to differences in phenotypes, but may also change over time for each individual in relation to factors such as age or breeding effort. Knowing the pattern of change for individuals is desirable for understanding when and how selection might act on variation. among individuals. Choice of the appropriate statistical models for analysis of survival patterns also is dependent upon the patterns of age-specific mortality.

Age-specific variation in survival rates of birds generally is not well known, because of the

\footnotetext{
${ }^{4}$ Present address: 410 Huron Avenue South, Ottawa, Ontario K1Y 0X1, Canada.

${ }^{5}$ Present address: Department of Biology, York University, North York, Ontario M3J 1P3, Canada.
}

many inherent difficulties in determining the fate of individuals, as well as the difficulty of obtaining large samples of older birds. Except in studies of relatively small or closed populations, in which nearly every individual can be found each year, survival rates for most populations must be inferred from a subsample of the original sample of marked individuals that were re-encountered, either when they died (recoveries) or when they were still alive (recaptures). The statistical difficulties inherent with such sampling for age-specific analysis were not recognized until relatively recently (Cavé 1977, Lakhani and Newton 1983, Anderson et al. 1985), with the result that many early survival estimates were based on inappropriate methods, and are unreliable. Although a number of modern statistical techniques have been developed, both for analysis of recovery data (e.g. Brownie et al. 1985) and recapture data (Clobert et al. 1987, Burnham et al. 1987, Pollock et al. 1990, Lebreton et al. 1992), relatively few 
studies have used these methods for a detailed analysis of age-specific survival patterns in birds.

Studies of many species have shown that recently fledged young birds have significantly lower survival rates than adults (e.g. Mallards, Anas platyrhynchos, Anderson 1975; Canada Geese, Branta canadensis, Samuel et al. 1990; Barnacle Geese, B. leucopsis, Owen and Black 1989; Yellow-eyed Juncos, Junco phaeonotus, Sullivan 1989; and Great Tits, Parus major, Clobert et al. 1988), and demographic considerations suggest this to be a general phenomenon (Lack 1954, Ricklefs 1973). Although much juvenile mortality is thought to occur in the first few days or weeks after fledging, relatively little is known about when survival rates of young birds reach those of older birds. Loery et al. (1987) showed that young Black-capped Chickadees ( $P$. atricapillus) marked in the winter several months after fledging were significantly less likely than adults to return the following winter, but the authors could not differentiate mortality from emigration. Ekman (1984) found evidence that Willow Tits ( $P$. montanus) experienced higher mortality throughout their first year of life, compared with older birds. Mark-recapture studies of nesting Great Tits in England suggested that yearlings, nesting for the first time, were significantly less likely to return than older birds (Clobert et al. 1988). In contrast, survival rates of young and adult Yellow-eyed Juncos appear to be similar after the first few months of life (Sullivan 1989), and yearling Blue Tits ( $P$ caeruleus) nesting in southern Europe actually had higher survival than adults (Blondel and Pradel 1990). Survival rates of young and adults do not appear to differ significantly after the end of the hunting season for Mallards (Hopper et al. 1978, Rakestraw 1981, Nichols and Hines 1987), but Barnacle Geese may have higher survival during their second year than adults (Owen and Black 1989).

Age-specific survival, after the first year, is potentially confounded with variation in survival due to breeding activity. There is some evidence that increased reproductive effort may lead to reduced survival in gulls, possibly because of energetic stress or risk associated with feeding or protecting the young (Pugesek and Diem 1990). Owen and Black (1989) attributed the higher survival of yearling Barnacle Geese to the fact that they do not incur the energetic costs of breeding. On the other hand, even if breeding has significant costs, it is equally pos- sible that nonbreeders in a natural population could have lower survival than breeders if they were competitively inferior individuals that were unable to gather enough resources to breed.

Changes in avian survival rates with old age also are poorly understood. It has been widely assumed that survival rates remain relatively constant once a bird becomes adult (Lack 1954, Ricklefs 1973), although Botkin and Miller (1974) pointed out that some sort of senescent decline is likely for physiological reasons. More recently, significant declines in survival have been demonstrated in a few seabirds including Blacklegged Kittiwakes (Rissa tridactyla, Coulson and Wooller 1976), Short-tailed Shearwaters (Puffinus tenuirostris; Bradley et al. 1989), and possibly California Gulls (Larus californicus, Pugesek 1987), although declines in the last species were attributed to increased reproductive effort rather than senescence. Among other birds, Loery et al. (1987) found a decline in survival rates of older Black-capped Chickadees, although their published data suggest a long-term decline in apparent survival for all age classes that may have confounded their analyses (note that apparent survival rates, as measured by recapture analyses, also are affected by changes in emigration rates). A recent review by Newton (1989) found evidence for a senescent decline in survival in several species, although most of the data sets he considered had relatively few data for the older age classes, so measurements of the extent of the decline could not be precise.

In this paper, we examine age-specific survival patterns for Lesser Snow Geese (Chen caerulescens caerulescens) using all of the available banding data for the population nesting around the lowlands of Hudson Bay and the Foxe Basin, and migrating south through the prairies to coastal Louisiana and Texas. Ideally, if we knew the fate of all marked individuals, we could develop life tables and determine the precise shape of the mortality curve using a variety of powerful statistical techniques. Unfortunately, although over 350,000 geese have been banded from this population, less than $15 \%$ of these birds were recovered when they died. Such data cannot be used to construct life tables for two main reasons. First, the proportion of surviving birds at the end of the study is not known, so the re-encounter rate (probability that a dead bird will be found and reported) cannot be calculated without making restrictive (and un- 
testable) assumptions about the shape of the mortality curves (Lakhani and Newton 1983). Second, the re-encounter rate may vary with age or time, thus confounding variation in survival rates (Burnham and Anderson 1979, Anderson et al. 1985). As a result, it is necessary to use models that allow for variation in recovery rates.

Most of the re-encounters of Lesser Snow Geese involved geese shot and reported by hunters. Some additional information on survival is available from geese recaptured or resighted alive in subsequent years after banding at one of the colonies (La Pérouse Bay). Multiple encounters per bird enable much more versatile hypothesis testing (Lebreton et al. 1992), but unfortunately the La Pérouse Bay recaptures are potentially strongly biased by emigration and nonrandom sampling (C. M. Francis in prep). For this reason, and because recapture data are not available from most colonies, we have relied primarily on hunting recoveries for most of our analyses. Appropriate analysis techniques have been developed for recovery data (Brownie et al. 1985), but survival rates and recovery probabilities can only be estimated for age classes that can be distinguished at banding. At most breeding colonies, these consist only of nearly fledged young and breeding adults, although large numbers of yearlings and nonbreeding adults were captured in two years at McConnell River. However, we demonstrate in this paper how comparisons among models, and measures of relative survival rate can be used to test additional hypotheses about age-specific survival even when the models do not permit estimation of the actual survival rates. We also use data from geese banded at different times of year to determine the timing of differential mortality of young and adults. Finally, we have supplemented the recovery data with information from the recaptures and resightings of geese at the La Pérouse Bay colony to permit age-specific analysis of older birds.

\section{METHODS}

Data collection. - Our analyses depend most heavily on data from the colony of Lesser Snow Geese nesting at La Pérouse Bay (LPB), near Churchill, Manitoba $\left(58^{\circ} \mathrm{N}, 94^{\circ} \mathrm{W}\right)$, which has been under intensive study since 1968. General field methods are described in Finney and Cooke (1978) and Rockwell et al. (1983), and we present here only those details relevant to survival analysis. Every year in late July or early Au- gust, when the adults were molting and before the young could fly, geese were rounded up and captured for banding. Excluding 1969 (when very few adults were banded), an average of 3,200 birds was banded each year from 1970 to 1978 . The average increased to 5,300 birds per year for 1979 through 1988 due to greater effort. In addition, over 11,000 of these birds have been recaptured in subsequent years. Birds were classified as adults (at least two years old), yearlings, or goslings based upon plumage, and their sex was determined by cloacal eversion. At LPB, too few yearlings were caught for use in recovery analyses.

We also obtained banding data from the Canadian Wildlife Service and the U.S. Fish and Wildlife Service for all of the other large-scale banding projects involving the midcontinental population of Lesser Snow Geese. Sufficient data were available for birds banded at four other breeding colonies, at migration stopover sites in the Dakotas and Missouri, and at wintering locations in Texas and Louisiana. Capture and banding methods at the other breeding colonies were similar to those at LPB. At Cape Henrietta Maria (CHM) on the western edge of the mouth of James Bay, Ontario $\left(55^{\circ} \mathrm{N}, 83^{\circ} \mathrm{W}\right)$, an average of 3,000 geese was banded every year between 1969 and 1979. At the McConnell and Tha-anne Rivers (MCC) in the Keewatin District, North West Territories $\left(60^{\circ} \mathrm{N}, 94^{\circ} \mathrm{W}\right)$, about 45,000 geese were banded in 12 seasons between 1954 and 1971, of which about 16,000 were neck-collared, and nearly 79,000 geese were banded between 1977 and 1978. On Southampton Island (SHI) at the north of Hudson Bay, N.W.T., nearly 30,000 geese were banded in five seasons between 1952 and 1979 from colonies at the mouth of the Boas River $\left(64^{\circ} \mathrm{N}, 86^{\circ} \mathrm{W}\right)$ and along East Bay $\left(64^{\circ} \mathrm{N}, 81^{\circ} \mathrm{W}\right)$. On Baffin Island (BAF), in the Franklin District, N.W.T., 21,000 geese were banded between Bowman Bay and the Koukdjuak River $\left(66^{\circ} \mathrm{N}, 73^{\circ} \mathrm{W}\right)$ in three seasons between 1961 and 1968. Ringing at all colonies included mostly flocks of breeding adults with goslings. Only a few yearlings or older nonbreeders are likely to be mixed with these flocks because they tend to molt earlier, and often migrate away from the breeding colony (Cooch 1961). Only at MCC in 1977 and 1978 were large flocks of nonbreeders, or failed breeders, captured somewhat earlier in the season than the breeding flocks. These flocks included many yearlings, which were distinguished from older birds by plumage characters.

At the migration stopovers and on the wintering grounds, geese were mostly captured using cannon nets on baited fields. In the Dakotas (DAK), 1,200 geese were banded in North Dakota $\left(46^{\circ} \mathrm{N}, 97^{\circ} \mathrm{W}\right)$, and 18,400 in South Dakota $\left(64^{\circ} \mathrm{N}, 86^{\circ} \mathrm{W}\right)$ in October and November between 1961 and 1976. In Missouri (MO), about 11,000 geese were banded $\left(40^{\circ} \mathrm{N}, 95^{\circ} \mathrm{W}\right)$ between 1956 and 1970 in the months of October through December. In Texas (TEX), nearly 28,000 geese were banded at several reserves in the northeastern part 
of the state (about $29^{\circ} \mathrm{N}$, between $94^{\circ} 00^{\prime} \mathrm{W}$ and $95^{\circ} 30^{\prime} \mathrm{W}$ ), during the winters of 1970-1971 through 1978-1979 mostly during the hunting season between November and February. Finally, in Louisiana (LOU), 13,800 geese were banded in or near Sabine National Wildlife Refuge $\left(29^{\circ} 50^{\prime} \mathrm{N}, 93^{\circ} 20^{\prime} \mathrm{W}\right)$ between 1968 and 1978 , primarily after the end of the hunting season in late January through early March (we excluded a few hundred birds banded in November and December). For all data sets, we excluded data from birds that were neck-collared, dyed or painted, except the neck-collared geese at MCC, which we analysed separately.

Data analysis. - We estimated survival based on recoveries reported to the U.S. Fish and Wildlife Service as of September 1989, enabling us to estimate survival rates up to 1987 . We restricted analyses to dead geese that had been reported as shot between September and February, including birds for which the month was recorded only as "hunting season" or "autumn." These restrictions allowed us to interpret recoveries in relation to hunting vulnerability, and excluded fewer than $5 \%$ of recoveries of dead geese. Altogether, we used data from about 46,500 recoveries.

When the data permitted, we used the models and methodology described by Brownie et al. (1985) for estimating survival, and generally follow their terminology. Survival rate $\left(S_{i}\right)$ is the probability that a bird alive in a particular age class at the time of banding in year $i$ will survive to the time of banding in year $i+1$. Recovery rate $\left(f_{i}\right)$ is the probability that an individual banded bird alive at the time of banding in year $i$ will be shot and retrieved during the hunting season in year $i$ (as defined above), and its band reported to the appropriate wildlife service. Apart from its necessity in the models, this parameter can be used to index the relative vulnerability of different age classes to hunting, assuming that the reporting rate (given that a bird has been shot) does not differ among age classes. In most cases, to avoid bias if birds change age or breeding status, we have presented direct recovery rates, which refer only to birds newly banded in year $i$. We also use the term indirect recovery rate, which is the probability that a bird alive at the time of banding in year $i$ will be recovered in any year after year $i$ (up to end of 1988 hunting season). For analysis of midseason data (from the Dakotas, Missouri and Texas), we considered direct recoveries to be those from the same season as the birds were banded.

Following Brownie et al. (1985), we estimated survival using the most-parsimonious model that adequately fitted the data, while still allowing estimation of the survival rates of interest. Except for the midseason banding data, all models presented were acceptable based upon the goodness-of-fit tests. In a few cases, tests comparing among models indicated that more-general models (that do not allow explicit estimation of parameters of interest) would provide a significantly better fit to the data. In such cases, the results from the simpler models are likely to be slightly biased. However, except where indicated, we do not believe that this bias substantially affected any of our conclusions. Where models do not fit the data well, Burnham et al. (1987:243-254) suggested using quasi-likelihood methods to adjust the standard errors of the estimates. We adjusted the estimates accordingly, although in no case was the adjustment greater than $15 \%$.

Geese were not banded in consecutive years at all breeding colonies, so actual survival rates could not always be estimated using the models of Brownie et al. (1985). Instead, we derived an estimator of relative survival rates using the ratios of indirect recovery rates. Based upon the mathematical background described in Brownie et al. (1985:9-12), the expected number of indirect recoveries $\left(R_{i}\right)$ from $n_{i}$ adults banded in year $i$, and recovered up to year $l$ can be written as:

$$
R_{i}=n_{i} S_{i} \sum_{j=i+1}^{l}\left(\prod_{k=i+1}^{i-1} S_{k}\right) f_{j},
$$

where $S_{i}$ and $f_{i}$ represent the survival and recovery rates, respectively, of adults in $i$. Similarly, the indirect recoveries $\left(R_{i}^{\prime}\right)$ from $n_{i}^{\prime}$ juveniles banded in year $i$ can be written as:

$$
R^{\prime}{ }_{i}=n_{i}^{\prime} S^{\prime}{ }_{i} \sum_{i=i+1}^{l}\left(\prod_{k=i+1}^{j-1} S_{k}\right) f_{j},
$$

where $S^{\prime}$ is the juvenile survival rate in year $i$. Assuming that survival and recovery rates of adults and juveniles are the same after the first year, the relative survival rates in year $i$ can be estimated by:

$$
S_{i}^{\prime} S_{i}=\left(R_{i}^{\prime} / n_{i}^{\prime}\right) /\left(R_{i} / n_{i}\right)
$$

This assumption, which is also required for the methods of Brownie et al. (1985), is not strictly valid for two reasons. First, recovery rates differ among migration routes (Francis and Cooke 1992a), which may cause bias for geese that emigrate to new breeding colonies. For immature males banded at LPB, nearly all of which emigrate to new colonies with different recovery rates, the bias was substantial (Francis and Cooke 1992b), so we excluded them from the analyses. However, for all of the larger colonies, which have much lower emigration rates, and for analyses based on females (which are highly philopatric), there will be little or no bias. This assumption also is violated because yearling rates differ slightly from those of adults (see below). For geese banded on the breeding grounds, this bias was small relative to the large differences observed between adults and young. For geese banded in migration, where the bias was relatively more important, we modified the estimators to include only indirect recoveries from at least two years after banding. In this fashion, we estimated survival over the first two years of life relative to that 
of adults over the same time period. To estimate the 95\% confidence limits of both types of estimates we used Monte Carlo simulations, assuming that the ratios for each age class were independently binomially distributed with mean $R_{i} / n_{i}$.

To evaluate whether the survival and recovery rates for yearlings were the same as those of adults, we used the tests proposed by Brownie et al. (1985:89$90)$ to compare models that allow goslings, yearlings, and adults to differ (e.g. model H3) with models that assume yearlings and adults have the same rates (e.g. model $\mathrm{H} 2$ ). We modified the tests slightly (to increase their power for detecting small differences that were in consistent directions across years) by using directional Z-tests rather than chi-square tests (Francis and Cooke 1992b). These tests can be carried out even when only goslings and adults are banded, but in this case, the model (H3) cannot provide explicit estimates of yearling survival or recovery rates. Only with the data from MCC, where large numbers of yearlings were banded, were we able to use a model $(\mathrm{H} 4)$ that can provide these estimates. To estimate the relative survival rates of yearlings, breeding adults and nonbreeding adults at $\mathrm{MCC}$, we also employed ratios of indirect recovery rates, determined using a method similar to that described above for estimating immature survival.

To evaluate whether newly banded adults differ in survival and recovery rates from adults that survived from the previous year, we used a test comparing a general model (M0) that allows these rates to differ, with a more restricted model (M1) that assumes they are the same (Brownie et al. 1985:38).

Although there were some significant differences between the blue morph and white morph in recovery and/or survival rates, due mainly to differences in migration routes (unpubl. data), we combined the color morphs for all analyses in this paper because the differences were relatively small (particularly at LPB) and, within each data set, the color ratios did not differ sufficiently among age classes to create a detectable bias. Similarly, there were slight differences between the sexes in recovery patterns (Francis and Cooke 1992b), but again, as noted above, these mostly were small, and not sufficient to bias the analyses. The only exceptions were in the recovery analyses of goslings banded at LPB and in the recapture analyses at LPB for which emigration of males causes substantial bias. For these analyses, we used only data for females.

When the recovery data were adequate for the models of Brownie et al. (1985), we used their Fortran programs, ESTIMATE and BROWNIE, to estimate recovery and survival rates. We used SURGE4 to estimate age-specific survival using recapture data (Clobert et al. 1987, Lebreton et al. 1992). Data manipulations, generation of recovery matrices, and additional statistical analyses were done using programs written by C.M.F. with SAS (SAS Institute 1985).

\section{RESULtS}

First-year survival. - We estimated survival rates of goslings relative to those of adults, for all colonies and years for which banding had taken place, using our method of calculating the ratio of indirect recovery rates (Eq. 3). Without exception, goslings banded just prior to fledging were less likely to survive the following year than adults banded at the same time (Table 1). These differences were significant at all colonies, in all years, except for three years at Cape Henrietta Maria, when the sample sizes were relatively small and the $95 \%$ confidence limits of the ratio included $100 \%$ (which would indicate equality of adult and juvenile survival rates). Relative survival rates varied considerably among years, with often quite large differences between adjacent years. For example, immature survival rates at two colonies in 1968 were nearly double those of the previous year (note that, unlike estimates derived from the models of Brownie et al. [1985], all of these relative survival estimates are statistically independent because they are based only on birds banded in that year). In years when estimates are available from more than one colony, survival was sometimes similar at several colonies (e.g. 1970), but in other years was much lower at one colony than others (e.g. 1965, 1978 or 1979). Overall, mean relative survival rates of young appeared to decrease from the southernmost colony at Cape Henrietta Maria to the northernmost colony on Baffin Island, although these means are not strictly comparable, because estimates do not come from the same range of years for each colony, and data too rarely are available from several colonies in the same year to carry out a meaningful analysis of variance.

The above analyses of geese banded just prior to fledging show that juveniles tended to have much lower survival than adults, but provide relatively little information on when most of the juvenile mortality occurs. To determine whether lower juvenile survival persisted after fledging and the early stages of migration, we examined data from geese that had already survived this period, and were banded during the autumn migration and on the wintering grounds.

We initially used model $\mathrm{H} 2$ of Brownie et al. (1985) to analyze survival and recovery rates for geese banded during the hunting season at migration stopovers in the Dakotas and Mis- 
TABLE 1. Estimated ratios of juvenile to adult survival rates for first year after banding for Lesser Snow Geese banded just prior to fledging at five breeding colonies around Hudson Bay and the Foxe Basin. Ratios calculated as described in text, assuming yearling survival is similar to that of adults, and expressed in percentages (with $95 \%$ confidence limits). If confidence limits include $100 \%$, juvenile and adult survival do not differ significantly. See text for approximate annual banding totals.

\begin{tabular}{|c|c|c|c|c|c|}
\hline \multirow[b]{2}{*}{ Year } & \multicolumn{5}{|c|}{ Breeding colony } \\
\hline & $\mathrm{CHM}$ & LPB & MCC & SHI & BAF \\
\hline 52 & - & - & - & $48(41-57)$ & - \\
\hline 53 & - & - & - & $43(37-49)$ & - \\
\hline 54 & - & - & $36(24-51)$ & - & - \\
\hline 55 & - & - & - & - & - \\
\hline 56 & - & - & - & - & - \\
\hline 57 & - & - & - & - & - \\
\hline 58 & - & - & - & - & - \\
\hline 59 & - & - & $56(45-70)$ & - & - \\
\hline 60 & - & - & $69(61-78)$ & $53(45-63)$ & - \\
\hline 61 & - & - & - & $23(16-30)$ & $9(7-12)$ \\
\hline 62 & - & - & - & - & - \\
\hline 63 & - & - & - & - & - \\
\hline 64 & - & - & $33(24-44)$ & - & - \\
\hline 65 & - & - & $20(16-24)$ & $39(28-51)$ & - \\
\hline 66 & - & - & $47(36-65)^{a}$ & - & - \\
\hline 67 & - & - & $31(23-39)^{a}$ & - & $24(15-34)$ \\
\hline 68 & - & - & $65(54-78)^{a}$ & - & $41(23-59)$ \\
\hline 69 & - & - & $47(36-60)^{a}$ & - & - \\
\hline 70 & $60(49-74)$ & $53(44-65)$ & $62(48-78)$ & - & - \\
\hline 71 & $39(10-80)$ & $63(48-83)$ & - & - & - \\
\hline 72 & $79(56-109)$ & $56(46-68)$ & - & - & - \\
\hline 73 & $49(34-66)$ & $73(61-88)$ & - & - & - \\
\hline 74 & $66(43-90)$ & $55(42-74)$ & - & - & - \\
\hline 75 & $84(63-113)$ & $76(61-95)$ & - & - & - \\
\hline 76 & $39(23-59)$ & $70(56-89)$ & - & - & - \\
\hline 77 & $83(60-115)$ & $63(51-78)$ & $63(57-69)$ & - & - \\
\hline 78 & $45(28-67)$ & $25(17-33)$ & $47(43-52)$ & - & - \\
\hline 79 & $69(56-86)$ & $38(31-47)$ & - & $39(26-55)$ & - \\
\hline 80 & - & $62(51-75)$ & - & - & - \\
\hline 81 & - & $29(22-37)$ & - & - & - \\
\hline 82 & - & $47(37-59)$ & - & - & - \\
\hline 83 & - & $22(14-33)$ & - & - & - \\
\hline 84 & - & $41(29-57)$ & - & - & - \\
\hline 85 & - & $32(22-47)$ & - & - & - \\
\hline 86 & - & $33(17-54)$ & - & - & - \\
\hline 87 & - & $51(26-97)$ & - & - & - \\
\hline Mean & 61.3 & 49.4 & 48.0 & 41.0 & 25.0 \\
\hline
\end{tabular}

"Both adults and young were neck-collared

souri, and at wintering areas in Texas. Recovery rates of immatures were two to three times higher than those of adults (Table 2) indicating that young geese remain more vulnerable to hunters throughout the hunting season. Consistent with this higher hunting mortality, survival estimates of young geese from the Dakotas were significantly lower than those for adults, but estimates from Missouri and Texas showed no significant difference in survival rates. However, the models we fitted for both the Dakotas and Missouri were strongly rejected by the tests in program BROWNIE, in favor of models al- lowing yearlings to have different survival and/ or recovery rates than adults (model $\mathrm{H} 2$ vs. $\mathrm{H} 3$; Dakotas $X^{2}=56.9, \mathrm{df}=16, P<0.0001$; Missouri $\left.X^{2}=34.0, \mathrm{df}=15, P=0.003\right)$. Unfortunately, exact survival estimates cannot be determined for any of the age classes based on model $\mathrm{H} 3$.

Instead, we estimated survival for young birds over their first two years of life, relative to survival for adults over the same period, modifying equation 3 to include only indirect recovery rates two or more years after banding. Mean estimated survival for young birds relative to adults for the first two years after banding, cal- 
TABLE 2. Estimated mean survival and recovery rates (\%) for immature and adult Lesser Snow Geese banded on breeding grounds, on migration, or on wintering grounds. Calculated for all data sets with several years of consecutive banding using models of Brownie et al. (1985). Direct recovery rates for Louisiana geese, which were banded at end of hunting season, refer to the following hunting season.

\begin{tabular}{|c|c|c|c|c|c|c|c|c|c|}
\hline \multirow[b]{2}{*}{ Location } & \multirow[b]{2}{*}{ Years } & \multicolumn{2}{|c|}{ No. banded } & \multicolumn{3}{|c|}{ Survival rate $(\bar{S} \pm S E)$} & \multicolumn{3}{|c|}{ Direct recovery rate $(F \pm S E)$} \\
\hline & & Young & Adults & Young & Adults & $P^{b}$ & Young & Adults & $P^{\mathbf{b}}$ \\
\hline $\begin{array}{l}\text { La Pérouse Bay } \\
\text { Cape Henrietta }\end{array}$ & $70-88$ & 53,531 & 26,859 & $42.4 \pm 1.9$ & $81.6 \pm 1.6$ & 0.0001 & $6.7 \pm 0.2$ & $3.8 \pm 0.2$ & 0.0001 \\
\hline Maria & $69-79$ & 13,773 & 16,362 & $47.8 \pm 3.1$ & $82.7 \pm 1.2$ & 0.0001 & $6.1 \pm 0.3$ & $2.7 \pm 0.2$ & 0.0001 \\
\hline Dakotas & $61-76$ & 8,538 & 10,507 & $65.8 \pm 4.1$ & $82.4 \pm 2.2$ & 0.0004 & $7.5 \pm 0.3$ & $3.4 \pm 0.2$ & 0.0001 \\
\hline Missouri & $61-70$ & 5,596 & 5,506 & $77.2 \pm 5.7$ & $78.8 \pm 1.7$ & 0.79 & $6.1 \pm 0.5$ & $3.0 \pm 0.3$ & 0.0001 \\
\hline Texas & $70-78$ & 5,612 & 23,088 & $79.6 \pm 4.7$ & $84.2 \pm 1.3$ & 0.34 & $1.3 \pm 0.2$ & $0.5 \pm 0.1$ & 0.001 \\
\hline Louisiana & $68-78$ & 2,421 & 11,359 & $92.4 \pm 6.4$ & $81.1 \pm 1.6$ & 0.09 & $2.7 \pm 0.4$ & $2.9 \pm 0.1$ & 0.06 \\
\hline
\end{tabular}

- Survival rates estimated using model H1 of Brownie et al. (1985) for breeding colonies and Louisiana, and model H2 for the Dakotas, Missouri, and Texas. Model H2 was strongly rejected $(P<0.01)$ for the Dakotas, Missouri and Texas in favor of model H3 allowing yearlings to differ from adults, so survival estimates may be biased (see text). Model $\mathrm{H} 3$ for Texas was rejected on a goodness-of-fit test $(P=0.02$ ), apparently due to heterogeneity among cohorts. Data from Lovisiana fit model Ho, which assumes adult and young have same survival and recovery rates

'Probability survival/recovery rates are same for both age classes ( $Z$-test).

culated in this manner, was $80 \pm \mathrm{SE}$ of $4.0 \%$ for birds banded in the Dakotas, and $84 \pm 5.7 \%$ for birds banded in Missouri, which are both significantly lower than $100 \%(P<0.05)$. If survival rates were the same for both young birds and yearlings, their annual survival rate, relative to adults, would be $(0.80)^{0.5}$, or about $90 \%$. If survival of yearlings was the same as that for adults, gosling survival could be as low as $80 \%$ of adult survival. Even the lower of these estimates indicates that survival rates of immatures that reached the migration stopovers are much more similar to those of adults than were survival rates of nearly fledged goslings (Table 1).

Despite the large difference in recovery rates, survival rates for goslings banded in Texas were only slightly lower than those for adults, and the difference was not significant. Although the model again was not a good fit, this did not appear to be due to any systematic bias, because models allowing yearlings to differ from young were still rejected by the general goodness-offit test $\left(X^{2}=223, \mathrm{df}=172, P<0.02\right)$. Possibly, the analyses were affected by heterogeneity in the data set caused by pooling data from several banding locations, which may differ in recovery rates, but the data were too sparse to analyze all data sets separately. In any case, the recovery estimates are probably not biased by this problem, and a relatively small difference between the age classes in survival is not surprising if differential hunting vulnerability is the main factor affecting goslings at this stage, because they had already survived much of the hunting season by the time they were banded, and recovery rates for both age classes were very low.

The sample of geese banded in Louisiana after the end of the hunting season suggests that there is no longer any difference between young and adults by this stage (Table 2). In fact, survival rates for young birds appear to be slightly higher than those of adults over the following year, and recovery rates slightly lower, although neither difference is significant. Note, however, that relatively few young birds were banded at this site.

Second-year survival. - If geese take more than one hunting season to become adept at avoiding hunters (or other sources of mortality), yearlings might be expected to be recovered relatively more often than adults, and to have lower survival. However, if there is a substantial cost to breeding, yearlings might have higher survival because they do not breed. The survival estimates for young geese from Louisiana, which include the period when these geese experience their second hunting season, suggest yearlings may not differ from adults, but the much larger data sets from the breeding grounds show significant differences.

Only the data from McConnell River in 1977 and 1978, when large numbers of yearlings were banded, can provide explicit estimates of recovery probabilities and relative survival rates. These data indicate that yearlings were nearly twice as likely to be shot as older nonbreeders $(P<0.0001)$, and slightly more likely to be shot than breeding adults $(P=0.03$; Table 3$)$. Possibly, as a consequence, they also had signifi- 
TABLE 3. Recovery rates and relative survival rates (with $95 \%$ confidence intervals) for yearlings, breeding adults, and nonbreeding adults banded at McConnell River in 1977 and 1978. Estimates of relative survival rates assume that surviving birds from all age classes have equal recovery rates in subsequent years.

\begin{tabular}{lccc}
\hline \hline & \multicolumn{1}{c}{1977} & 1978 & Mean \\
\hline & \multicolumn{1}{c}{ Direct recovery rates (\%) } & \\
Breeders & $2.60(2.20-3.00)$ & $2.81(2.54-3.08)$ & $2.71(2.46-2.95)$ \\
Yearlings & $3.15(2.60-3.70)$ & $3.11(2.67-3.55)$ & $3.13(2.78-3.48)$ \\
Nonbreeders & $1.50(1.20-1.81)$ & $2.01(1.82-2.19)$ & $1.75(1.58-1.93)$ \\
& \multicolumn{1}{c}{ Relative survival rates (\%) } & \\
Yearlings/breeders & $87.0(76.9-98.5)$ & $94.8(85.5-104.7)$ & $90.9(83.7-98.1)$ \\
Yearlings/nonbreeders & $97.9(86.5-110.7)$ & $91.8(83.3-101.6)$ & $94.8(87.2-102.4)$ \\
Nonbreeders/breeders & $88.8(79.8-99.3)$ & $103.3(96.6-110.8)$ & $96.0(90.0-102.0)$ \\
\hline \multicolumn{2}{l}{ "Estimated as ratio of proportions of indirect recoveries for each age class (as in Table 1). If 95\% confidence limits include 100\%, age classes do } \\
not differ significantly.
\end{tabular}

cantly lower survival rates than breeding adults, although survival did not differ significantly from older nonbreeders (Table 3).

Data from indirect recoveries of goslings banded at four of five breeding colonies confirm the generality of the differences in survival and/ or recovery rates between yearlings and older geese (Table 4). At all colonies except Baffin Island, which had a very small sample size, a significantly higher proportion of indirect recoveries of goslings came from the second year after banding in comparison to adults banded in the same or previous years. Although the differences were small in most years, all significant differences were in the same direction, and the combined $Z$-tests were highly significant (Table 4). These results indicate that yearlings, relative to adults, had higher recovery rates, lower survival rates (so that fewer birds were available to be recovered in subsequent years), or both. These explanations cannot be distinguished because the number of geese that survived to become yearlings is not known. The estimates of juvenile survival rate in Tables 1 and 2 are dependent on the assumption that yearlings do not differ from adults. If yearlings have higher recovery rates than adults, then gosling survival rates will be overestimated, while if yearlings have lower survival, gosling survival will be underestimated. The precise balance of these biases may vary among colonies, but is unlikely to be more than a few percent based on the estimates derived from McConnell River.

Breeding status. - The only available sample of nonbreeding adults was from McConnell River in 1977 and 1978. In these two years, nonbreeding adults were much less likely to be shot than either breeding adults or yearlings (Table 3 ). Despite this difference, their survival rates in 1977 were actually slightly lower than those of breeding adults, although the mean difference over both years was not significant. Many of these nonbreeders are probably two- or threeyear-old geese which are less likely to breed than older birds (Sulzbach 1975). Some may also be geese that had bred in previous years, but either refrained from nesting, or attempted and failed due to loss of eggs or goslings to predators.

If failing to breed in one year, after breeding successfully the previous year, occurs fairly frequently, and if these geese have lower recovery rates than breeders, then we can predict that newly banded geese (most of which have goslings) should be more likely to be recovered than geese that survived from previous cohorts (at least some of which presumably failed). This hypothesis can be tested by comparing a model that allows these rates to differ (model M0) with a model that assumes they are the same (model M1; Brownie et al. 1985:38). The hypothesis that newly banded breeding geese have higher recovery rates is strongly supported by the banding data for adults of both sexes from La Pérouse Bay (Table 5). It also is consistent with the data from Cape Henrietta Maria, although the overall $Z$ is not significant. At La Pérouse Bay, the ratio of direct to indirect recoveries was significantly higher for newly banded adults than survivors from previous cohorts that were not necessarily caught. This indicates that the former group had higher recovery rates and/or lower survival rates than the latter, but as with the analysis for yearlings, these hypotheses cannot be distinguished using these data because 
TABLE 4. Relative vulnerability/survival of yearlings compared with adults. Ratios greater than one indicate that yearlings were more likely to be recovered and/or had lower survival rates than adults. Yearling sample consists of birds banded as goslings the previous year, while adult sample includes all birds banded in any previous year that were at least two years old in indicated year. ${ }^{a}$

\begin{tabular}{lcccc}
\hline \hline Year & Yearlings & Adults & Ratio & $Z^{\mathrm{b}}$ \\
\hline \multicolumn{5}{c}{ La Pérouse Bay, Manitoba (females) } \\
71 & $35: 88$ & $11: 76$ & 2.75 & $2.73^{* *}$ \\
72 & $12: 50$ & $44: 161$ & 0.88 & -0.36 \\
73 & $26: 78$ & $48: 236$ & 1.64 & 1.80 \\
74 & $31: 110$ & $75: 307$ & 1.15 & 0.59 \\
75 & $15: 41$ & $97: 351$ & 1.32 & 0.87 \\
76 & $43: 109$ & $114: 319$ & 1.10 & 0.47 \\
77 & $25: 97$ & $91: 381$ & 1.10 & 0.30 \\
78 & $32: 94$ & $153: 371$ & 0.83 & -0.85 \\
79 & $7: 28$ & $121: 400$ & 0.83 & -0.44 \\
80 & $20: 70$ & $95: 414$ & 1.25 & 0.79 \\
81 & $25: 89$ & $131: 424$ & 0.91 & -0.39 \\
82 & $19: 30$ & $135: 429$ & 2.01 & $2.30^{*}$ \\
83 & $30: 49$ & $149: 357$ & 1.47 & 1.53 \\
84 & $4: 14$ & $162: 283$ & 0.50 & -1.23 \\
85 & $13: 21$ & $117: 220$ & 1.16 & 0.41 \\
86 & $9: 9$ & $110: 162$ & 1.47 & 0.80 \\
87 & $9: 0$ & $111: 75$ & - & $2.43^{*}$ \\
Total & & & & $2.85^{* *}$
\end{tabular}

Cape Henrietta Maria, Ontario

$\begin{array}{lcrrr}70 & 38: 103 & 53: 168 & 1.17 & 0.64 \\ 71 & 57: 114 & 118: 338 & 1.43 & 1.85 \\ 72 & 3: 1 & 122: 405 & 9.96 & 2.44^{*} \\ 73 & 12: 51 & 71: 415 & 1.38 & 0.92 \\ 74 & 9: 38 & 138: 473 & 0.81 & -0.55 \\ 75 & 7: 30 & 178: 531 & 0.70 & -0.85 \\ 76 & 26: 74 & 140: 500 & 1.25 & 0.92 \\ 77 & 13: 20 & 127: 506 & 2.59 & 2.66^{* *} \\ 78 & 19: 46 & 156: 441 & 1.17 & 0.54 \\ 79 & 5: 20 & 163: 396 & 0.61 & -0.99 \\ 80 & 37: 96 & 113: 470 & 1.60 & 2.16^{*} \\ \text { Total } & & & & 2.94^{*}\end{array}$

McConnell River, N.W.T.

$\begin{array}{lcccc}55 & 13: 37 & 14: 53 & 1.33 & 0.65 \\ 60 & 22: 87 & 47: 204 & 1.10 & 0.32 \\ 61 & 95: 256 & 168: 555 & 1.22 & 1.37 \\ 65 & 11: 37 & 182: 510 & 0.83 & -0.52 \\ 66 & 30: 101 & 194: 801 & 1.23 & 0.92 \\ 71 & 31: 58 & 114: 454 & 2.13 & 3.12^{* *} \\ 77 & 173: 402 & 317: 1262 & 1.71 & 4.90^{* * *} \\ 78 & 107: 357 & 1422: 4013 & 0.84 & -1.46 \\ \text { Total } & & & & 3.28^{* *}\end{array}$

Southampton Island, N.W.T.

$\begin{array}{lcccc}53 & 62: 272 & 39: 132 & 0.77 & -1.13 \\ 54 & 111: 175 & 338: 895 & 1.68 & 3.81^{* * *} \\ 58 & 1: 5 & 436: 1190 & 0.55 & -0.56 \\ 61 & 70: 148 & 268: 870 & 1.53 & 2.68^{*} \\ 62 & 10: 31 & 341: 1572 & 1.49 & 1.08 \\ 66 & 13: 33 & 270: 959 & 1.40 & 1.01 \\ 79 & 11: 29 & 20: 66 & 1.25 & 0.52 \\ \text { Total } & & & & 2.80^{* *}\end{array}$

TABLE 4. Continued.

\begin{tabular}{lcrcc}
\hline \hline Year & Yearlings & Adults & Ratio & $Z^{\mathrm{b}}$ \\
\hline \multicolumn{5}{c}{ Baffin Island, N.W.T. } \\
62 & $10: 39$ & $201: 749$ & 0.96 & -0.13 \\
68 & $3: 27$ & $52: 389$ & 0.85 & -0.26 \\
69 & $4: 15$ & $332: 996$ & 0.80 & -0.40 \\
Total & & & & -0.45 \\
\hline
\end{tabular}

$* P<0.05 * * P<0.01 ; * * P<0.001$.

"For example, entry for La Pérouse Bay in 1971 indicates that, of goslings banded in 1970, there were 35 recoveries as yearlings in 1971 and 88 recoveries in subsequent years. For adults banded in 1970 (or earlier), only 11 were recovered in 1971 , compared with 76 in subsequent years.

' $Z$ is square root of standard chi-square from $2 \times 2$ contingency table, and is approximately normally distributed with mean zero and variance one under the null hypothesis. Total $Z$-statistic is unweighted sum of $Z$-statistics divided by $n^{0.5}$ and also is normally distributed with mean zero and variance one.

we do not have an independent estimate of the number of surviving adults. If we assume that the survival rates are the same for both groups (as is done by model M0), then the mean recovery rates for newly banded birds can be estimated as $3.6 \pm 0.17 \%$ for males and $3.7 \pm$ $0.20 \%$ for females, while the recovery rates for birds banded in previous years are $2.9 \pm 0.16 \%$ and $3.0 \pm 0.18 \%$, respectively. If this drop is caused entirely by nonbreeding in subsequent years, and if we assume that recovery rates of nonbreeders are half those of breeders, then a 15 to $20 \%$ drop in recovery rates would indicate that 30 to $40 \%$ of geese failed to breed in years after they were first caught as successful breeders.

The sample of previously banded birds in the above analysis includes some birds that were recaptured in subsequent years and, thus, presumably breeding in both years. If we compare the recovery patterns of these older breeders after their second capture, with those for geese newly captured in the same year, we find some evidence that newly banded geese actually have lower survival rates. Recaptured geese that had been banded as adults at La Pérouse Bay in previous years had similar direct recovery rates to newly banded birds, but had significantly higher indirect recovery rates (Table 6). Assuming that recovery rates for survivors from both groups were similar in subsequent years, this indicates that newly banded geese had lower survival rates, on average, than geese that were caught in the same year, but had been caught on at least one previous occasion. The difference in mean indirect recovery rates suggests that 
TABLE 5. Relative vulnerability/survival of newly captured breeding adults compared with adults captured in previous years. Ratios greater than one indicate that newly caught breeding adults were more likely to be recovered and/or had lower survival rates than survivors from previous cohorts. ${ }^{\text {a }}$

\begin{tabular}{|c|c|c|c|c|}
\hline Year & $\begin{array}{l}\text { Newly } \\
\text { ringed } \\
\text { adults }\end{array}$ & $\begin{array}{l}\text { Previously } \\
\text { ringed } \\
\text { adults }\end{array}$ & Ratio & $Z$ \\
\hline \multicolumn{5}{|c|}{ La Pérouse Bay, Manitoba (females) } \\
\hline 71 & $8: 41$ & $11: 76$ & 1.35 & 0.60 \\
\hline 72 & $33: 73$ & $29: 88$ & 1.37 & 1.06 \\
\hline $7 \overline{3}$ & $25: 68$ & $20: 141$ & 2.59 & $2.91^{* *}$ \\
\hline 74 & $11: 31$ & $43: 166$ & 1.37 & 0.81 \\
\hline 75 & $13: 41$ & $51: 146$ & 0.91 & -0.27 \\
\hline 76 & $20: 44$ & $49: 138$ & 1.28 & 0.78 \\
\hline 77 & $18: 46$ & $36: 146$ & 1.59 & 1.39 \\
\hline 78 & $24: 56$ & $56: 136$ & 1.04 & 0.14 \\
\hline 79 & $30: 81$ & $40: 152$ & 1.41 & 1.23 \\
\hline 80 & $20: 71$ & $41: 192$ & 1.32 & 0.91 \\
\hline 81 & $27: 51$ & $56: 207$ & 1.96 & $2.41^{*}$ \\
\hline 82 & $24: 47$ & $67: 191$ & 1.46 & 1.31 \\
\hline 83 & $17: 39$ & $71: 167$ & 1.03 & 0.08 \\
\hline 84 & $18: 40$ & $81: 125$ & 0.69 & -1.15 \\
\hline 85 & $18: 31$ & $57: 108$ & 1.10 & 0.28 \\
\hline 86 & $14: 15$ & $54: 85$ & 1.47 & 0.94 \\
\hline 87 & $21: 14$ & $67: 33$ & 0.74 & -0.75 \\
\hline Total & & & & $3.07^{* *}$ \\
\hline \multicolumn{5}{|c|}{ La Pérouse Bay, Manitoba (males) } \\
\hline 71 & $12: 59$ & $11: 60$ & 1.11 & 0.23 \\
\hline 72 & $38: 87$ & $32: 87$ & 1.19 & 0.61 \\
\hline 73 & $32: 82$ & $33: 141$ & 1.67 & 1.81 \\
\hline 74 & 22.51 & $58: 165$ & 1.23 & 0.69 \\
\hline 75 & $23: 50$ & $49: 167$ & 1.57 & 1.51 \\
\hline 76 & $24: 75$ & $54: 163$ & 0.97 & -0.12 \\
\hline 77 & $14: 91$ & $42: 196$ & 0.72 & -1.00 \\
\hline 78 & $28: 68$ & $72: 215$ & 1.23 & 0.79 \\
\hline 79 & $40: 104$ & $69: 214$ & 1.19 & 0.76 \\
\hline 80 & $37: 91$ & $72: 246$ & 1.39 & 1.39 \\
\hline 81 & $26: 84$ & $78: 259$ & 1.03 & 0.10 \\
\hline 82 & $33: 94$ & $62: 281$ & 1.59 & 1.90 \\
\hline 83 & $26: 51$ & $109: 266$ & 1.24 & 0.82 \\
\hline 84 & $24: 44$ & $89: 228$ & 1.40 & 1.19 \\
\hline 85 & $27: 46$ & $92: 180$ & 1.15 & 0.51 \\
\hline 86 & $13: 32$ & $82: 144$ & 0.71 & -0.95 \\
\hline 87 & $34: 10$ & $100: 76$ & 2.58 & $2.49^{*}$ \\
\hline Total & & & & $3.08^{* *}$ \\
\hline \multicolumn{5}{|c|}{ Cape Henrietta Maria, Ontario } \\
\hline 70 & $55: 185$ & $53: 168$ & 0.94 & -0.27 \\
\hline 71 & $26: 75$ & $85: 268$ & 1.09 & 0.34 \\
\hline 72 & $18: 80$ & $75: 268$ & 0.80 & -0.75 \\
\hline 73 & $25: 145$ & $51: 297$ & 1.00 & 0.02 \\
\hline 74 & $48: 198$ & $91: 351$ & 0.94 & -0.34 \\
\hline 75 & $28: 79$ & $130: 419$ & 1.14 & 0.55 \\
\hline 76 & $26: 59$ & $111: 387$ & 1.54 & 1.67 \\
\hline 77 & $30: 71$ & $85: 361$ & 1.79 & $2.37^{*}$ \\
\hline 78 & $25: 72$ & $115: 317$ & 0.96 & -0.17 \\
\hline 79 & $73: 167$ & $117: 272$ & 1.02 & 0.09 \\
\hline Total & & & & 1.11 \\
\hline
\end{tabular}

* $P<0.05 ;{ }^{* *} P<0.01 ; * * P<0.001$.

"Statistics calculated as in Table 4. newly banded birds have about $10 \%$ lower survival rates than experienced geese.

Overall, the analysis of nonbreeding adults at McConnell River in 1977 and 1978 clearly indicates that they have lower recovery rates than breeding adults, but the analyses from La Pérouse Bay are less easily interpreted. If all adults captured in a year had bred, regardless of when they were first banded, some of the differences must have been unrelated to breeding status. Possibly, geese continue to gain experience, even after they start breeding, that increases their survival probabilities. Alternatively, geese that are less able to survive, for whatever reason, may be selected against, leaving only better-quality geese to return in the future. Nevertheless, this does not preclude the possibility that the recovery/survival rates of previously banded geese were also affected by geese that failed to breed. The difference between newly banded geese and geese from previous years that were recaptured is only about one-half the difference between newly banded geese and all previously banded geese (including those that were not captured). Some of the additional difference may well be due to nonbreeding, but the uncertainties of these figures are too large to obtain a reliable estimate of the proportion.

Senescence.-Although the tests used to compare yearling survival with adult survival theoretically could be extended to test for differences in survival among older age classes, the tests become increasingly difficult to interpret because of the complex assumptions required concerning the age distribution of the newly banded adults. Instead, we used additional information from birds recaptured in subsequent years to test for systematic changes in survival rate with age in older birds. We initially compared the recovery probabilities of individuals as a function of age, to test whether older individuals were more likely to be recovered than younger birds, possibly indicating greater vulnerability to hunting. For birds of known exact age that had been banded as goslings or yearlings, there was no significant linear relationship between age at recapture and probability of being recovered the following hunting season (Table 7). However, for geese banded as breeding adults when they were at least two years old, and recaptured in subsequent years, there was a marginally significant $(P=0.03)$ tendency for older geese to be more vulnerable 
TABLE 6. Direct and indirect recovery rates for geese captured for first time, and for recaptured geese that had been ringed in previous years. Lower proportion of indirect recoveries for newly captured geese suggests that fewer survived the first year. The $Z$ is calculated as square root of contingency chi-square comparing proportion recovered to proportion not recovered. Both composite Z-test and Mantel-Haenszel test are sensitive to overall trends across years, but former weights all years equally, while latter is most strongly influenced by years with largest sample sizes.

\begin{tabular}{|c|c|c|c|c|c|c|c|c|}
\hline \multirow[b]{2}{*}{ Year } & \multicolumn{2}{|c|}{ Number caught } & \multicolumn{3}{|c|}{ Direct recovery rates ${ }^{a}$} & \multicolumn{3}{|c|}{ Indirect recovery rates ${ }^{b}$} \\
\hline & New & Recaptures & New & Recaptures & $Z$ & New & Recaptures & $Z$ \\
\hline 71 & 562 & 85 & 3.6 & 1.2 & -1.15 & 17.8 & 15.3 & -0.56 \\
\hline 72 & 1,113 & 275 & 6.5 & 4.7 & -1.08 & 14.4 & 16.4 & 0.83 \\
\hline 73 & 1,062 & 311 & 5.4 & 4.2 & -0.84 & 14.1 & 16.4 & 1.00 \\
\hline 74 & 647 & 305 & 5.1 & 5.9 & 0.51 & 12.7 & 14.1 & 0.61 \\
\hline 75 & 657 & 312 & 5.5 & 4.8 & -0.44 & 13.9 & 13.8 & -0.03 \\
\hline 76 & 996 & 292 & 4.3 & 6.2 & 1.31 & 11.9 & 13.4 & 0.64 \\
\hline 77 & 1,038 & 432 & 3.1 & 3.5 & 0.39 & 13.2 & 13.9 & 0.35 \\
\hline 78 & 994 & 264 & 5.1 & 6.4 & 0.84 & 12.2 & 14.4 & 0.96 \\
\hline 79 & 1,841 & 432 & 3.6 & 4.2 & 0.52 & 9.5 & 14.4 & $2.96^{* *}$ \\
\hline 80 & 1,745 & 663 & 3.3 & 2.1 & -1.50 & 9.1 & 10.9 & 1.35 \\
\hline 81 & 1,569 & 622 & 3.2 & 3.1 & -0.16 & 8.3 & 10.9 & 1.90 \\
\hline 82 & 1,674 & 665 & 3.3 & 3.2 & -0.16 & 8.0 & 8.7 & 0.57 \\
\hline 83 & 1,483 & 637 & 2.9 & 3.3 & 0.49 & 5.9 & 6.8 & 0.78 \\
\hline 84 & 1,577 & 487 & 2.6 & 2.5 & -0.17 & 5.2 & 6.6 & 1.16 \\
\hline 85 & 2,064 & 475 & 2.1 & 1.7 & -0.56 & 3.6 & 3.6 & -0.06 \\
\hline 86 & 1,758 & 510 & 1.5 & 1.4 & -0.18 & 2.6 & 2.7 & 0.16 \\
\hline 87 & 2,110 & 452 & 2.6 & 2.0 & -0.76 & 1.0 & 0.7 & -0.74 \\
\hline
\end{tabular}

Composite $Z=-0.71$, n.s; Mantel-Haenszel $X^{2}=0.36$, n.s.

${ }^{\circ}$ Composite $Z=2.88, P<0.01$; Mantel-Haenszel $X^{2}=11.42, P<0.001$

to hunters, although the difference was only apparent when data from all years are pooled (Table 7).

In contrast, there were no significant changes with age in indirect recovery rates, which are an index of survival rates, either for geese of known exact age, or for geese of known minimum age (Table 7). This suggests that although older geese may become slightly more vulnerable to hunters, this does not produce any detectable change in their survival rates.

Although the above test is probably the most appropriate means of detecting senescent effects in survival based on recoveries, it does not provide any estimate of the actual survival rates, or how much of a decline we could be overlooking. To do this, we have devised a composite analysis based on recoveries of birds of known minimum age. This method involved recalculating mean survival rates after progressively deleting the younger age classes. We initially estimated the mean survival rate from 1979 onwards for all adults caught for the first time during this period, using model M2 of Brownie et al. (1985). This model assumes that adult survival does not change over time, which is not strictly true (Francis et al. 1992), but provides a reasonable approximation if the time period is restricted to 1979 onwards. We then calculated the same estimate using only geese that were recaptured at least one year after initial banding, thus effectively removing the influence of younger geese on the estimates. We were able to continue in this manner up to eight years after banding (i.e. at least 10 years old) before the data became too sparse to produce an estimate, but we found no evidence for any change in survival rates, indicating that survival rates over the first 8 to 10 years as breeding adults are similar to those of older birds (Fig. 1).

Age-specific survival rates can also be estimated using recapture data both for birds of known exact age, and for birds of known minimum age. Because males usually emigrate from the colony when they choose a new mate (Cooke et al. 1975), we have restricted these analyses to females. These estimates are potentially affected by two types of nonrandom sampling. Younger geese are less likely to be captured because they breed less frequently, but this can be incorporated into the models by allowing recapture probabilities to be age dependent up to four years of age. In addition, at least for geese banded as adults, recapture probabilities appear to vary among individuals in different parts of the colony. The colony has been ex- 
TABLE 7. Mean direct $(d)$ and indirect (i) recovery rates of adult geese by age class, and correlations between age and recovery rates (calculated from ungrouped data such that all birds are weighted equally). MantelHaenszel chi-square tests for significant correlations between age and recovery rate after controlling for differences in recovery rates among years.

\begin{tabular}{|c|c|c|c|c|c|c|c|c|c|c|c|}
\hline \multirow[b]{3}{*}{ Year } & \multicolumn{9}{|c|}{ Mean recovery rates for age } & & \\
\hline & \multicolumn{3}{|c|}{$3-5$} & \multicolumn{3}{|c|}{$6-10$} & \multicolumn{3}{|c|}{$11-20$} & \multicolumn{2}{|c|}{ Correlations } \\
\hline & $n$ & $d$ & $i$ & $n$ & $d$ & $i$ & $n$ & $d$ & $i$ & $r_{\mathrm{d}}$ & $r_{\mathrm{i}}$ \\
\hline \multicolumn{12}{|c|}{ Known exact age ${ }^{a}$} \\
\hline 75 & 106 & 2.8 & 18.9 & 6 & 0.0 & 33.3 & - & - & - & -0.07 & 0.12 \\
\hline 76 & 155 & 5.2 & 12.3 & 39 & 2.6 & 15.4 & - & - & - & 0.02 & 0.05 \\
\hline 77 & 134 & 5.2 & 13.4 & 43 & 4.7 & 14.0 & - & - & - & 0.00 & -0.04 \\
\hline 78 & 119 & 6.7 & 10.9 & 44 & 9.1 & 13.6 & - & - & - & 0.11 & 0.11 \\
\hline 79 & 222 & 5.9 & 7.7 & 105 & 5.7 & 10.5 & - & - & - & 0.01 & 0.07 \\
\hline 80 & 298 & 3.0 & 8.7 & 95 & 3.2 & 11.6 & 3 & 0.0 & 0.0 & 0.01 & 0.03 \\
\hline 81 & 209 & 4.3 & 5.7 & 120 & 1.7 & 10.0 & 14 & 14.3 & 0.0 & 0.01 & 0.02 \\
\hline 82 & 230 & 1.3 & 9.6 & 125 & 5.6 & 6.4 & 11 & 0.0 & 0.0 & 0.04 & -0.04 \\
\hline 83 & 264 & 3.0 & 5.7 & 114 & 1.8 & 7.0 & 17 & 5.9 & 11.8 & -0.01 & 0.01 \\
\hline 84 & 259 & 2.3 & 2.7 & 113 & 4.4 & 6.2 & 29 & 3.4 & 6.9 & 0.06 & 0.05 \\
\hline 85 & 225 & 2.2 & 1.3 & 129 & 2.3 & 2.3 & 20 & 5.0 & 0.0 & 0.03 & -0.02 \\
\hline 86 & 157 & 2.5 & 2.5 & 107 & 0.0 & 0.9 & 20 & 0.0 & 0.0 & -0.08 & -0.09 \\
\hline 87 & 139 & 2.9 & 2.2 & 118 & 0.0 & 0.8 & 20 & 0.0 & 0.0 & -0.09 & -0.06 \\
\hline \multicolumn{12}{|c|}{ Known minimum age ${ }^{\mathrm{b}}$} \\
\hline 75 & 236 & 4.2 & 14.0 & 76 & 6.6 & 13.2 & - & - & - & 0.057 & 0.046 \\
\hline 76 & 195 & 5.1 & 12.3 & 97 & 8.2 & 15.5 & - & - & - & 0.061 & 0.046 \\
\hline 77 & 255 & 2.4 & 14.9 & 177 & 5.1 & 12.4 & - & - & - & 0.086 & -0.025 \\
\hline 78 & 187 & 7.0 & 14.4 & 76 & 5.3 & 13.2 & 1 & 0.0 & 100.0 & 0.008 & 0.020 \\
\hline 79 & 263 & 4.6 & 16.3 & 155 & 3.2 & 11.0 & 14 & 7.1 & 14.3 & 0.007 & -0.077 \\
\hline 80 & 471 & 2.3 & 12.1 & 161 & 1.2 & 8.1 & 31 & 3.2 & 6.5 & 0.009 & -0.054 \\
\hline 81 & 481 & 2.7 & 11.2 & 107 & 3.7 & 6.5 & 34 & 5.9 & 20.6 & 0.058 & 0.025 \\
\hline 82 & 506 & 2.0 & 9.5 & 119 & 7.6 & 6.7 & 40 & 5.0 & 5.0 & $0.078^{*}$ & -0.043 \\
\hline 83 & 428 & 3.7 & 5.4 & 174 & 2.9 & 10.3 & 35 & 0.0 & 5.7 & -0.029 & 0.062 \\
\hline 84 & 302 & 2.6 & 6.3 & 163 & 2.5 & 8.0 & 22 & 0.0 & 0.0 & -0.023 & -0.032 \\
\hline 85 & 293 & 2.0 & 3.8 & 156 & 1.3 & 3.2 & 26 & 0.0 & 3.8 & -0.032 & -0.004 \\
\hline 86 & 308 & 0.6 & 2.6 & 180 & 2.2 & 3.3 & 22 & 4.5 & 0.0 & $0.114^{*}$ & -0.028 \\
\hline 87 & 269 & 1.9 & 0.7 & 161 & 2.5 & 0.6 & 22 & 0.0 & 0.0 & 0.011 & -0.024 \\
\hline
\end{tabular}

$* P<0.05$

"Mantel-Haenszel test: direct, $X^{2}=0.53, P=0.57$; indirect, $X^{2}=0.33, P=0.56$.

'Mantel-Haenszel test: direct, $X^{2}=4.93, P=0.03$; indirect, $X^{2}=0.83, P=0.36$

panding over the course of the study (Cooch et al. 1989), and geese nesting in some areas are significantly more likely to be caught than others. This creates a potentially serious bias that cannot be incorporated into the models. Simulations have shown that such heterogeneity of recapture probabilities will depress the estimate of survival the first year after banding, and may create an appearance of decreased survival in older birds (Buckland 1982).

Model-selection procedures in program SURGE4 (Lebreton et al. 1992) indicated substantial annual variation in survival estimates, particularly for juveniles and newly banded adults. To increase precision in detecting changes in mean age-specific survival rates, we elected to use models that ignore this annual variation at the potential risk of increased bias.
Despite this limitation, and the potential bias due to nonrandom sampling, neither the survival estimates for female snow geese banded as goslings (Fig. 2) nor those for females banded as adults (Fig. 3) provide any indication of declining survival rates with old age, although the asymptotic $95 \%$ confidence limits for older age classes are extremely wide. Likelihood-ratio tests (Lebreton et al. 1992) indicated that the model allowing gosling survival to vary continuously with age did not differ significantly from a model in which survival is assumed to remain constant with age after the first year $\left(X^{2}\right.$ $=14.0, \mathrm{df}=13, P=0.4$; note that very few geese were captured as yearlings, so the data lack sufficient precision to detect the depressed survival of yearlings that was apparent from recovery data). The model for birds banded as adults sug- 


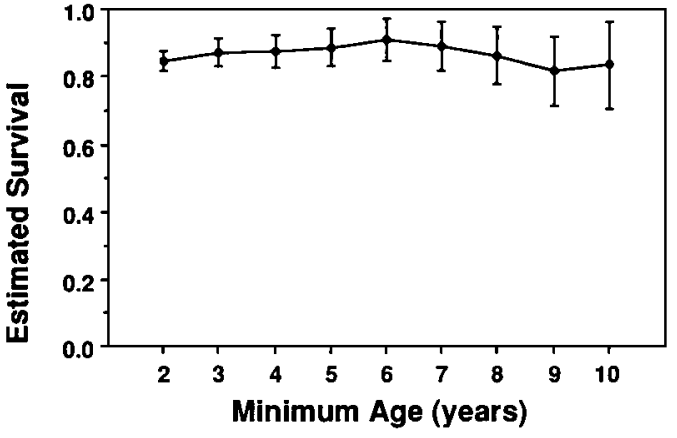

Fig. 1. Mean survival rates with approximate $95 \%$ confidence limits, estimated using model M2 of Brownie et al. (1985) for female Lesser Snow Geese of known minimum age captured and banded at $\mathrm{La}$ Pérouse Bay, Manitoba. Estimates do not differ significantly from each other.

gests they have extremely low survival rates in the first year after they are banded. This difference is much greater than the $10 \%$ difference suggested by the analysis of recoveries from recaptured geese, and simulations suggest it may be due mainly to the heterogeneity of recapture probabilities among individuals (unpubl. data). However, after the first year, there again was no evidence of any significant changes in survival with age $\left(X^{2}=16.4, \mathrm{df}=13, P=0.2\right)$.

\section{DISCUSSION}

Overall, our analyses indicate that survival rates are age dependent for at least the first two years of life, and that they are modified by

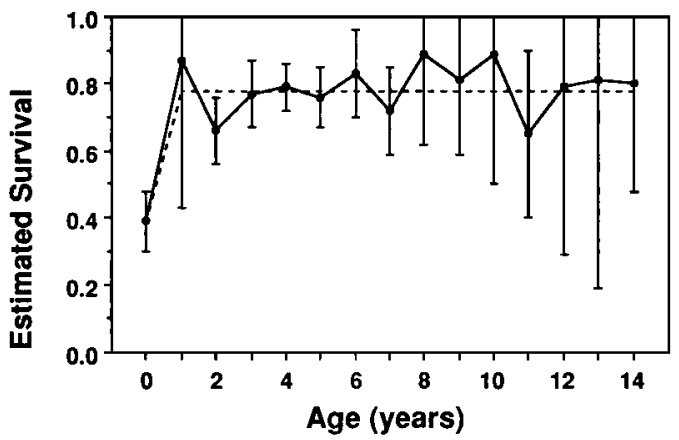

Fig. 2. Mean age-specific survival rates with approximate $95 \%$ confidence limits for female Lesser Snow Geese banded as goslings at La Pérouse Bay, Manitoba. Estimated from recapture information using program SURGE4 (Clobert et al. 1987). Estimates do not differ significantly from dashed line indicating no change after the first year.

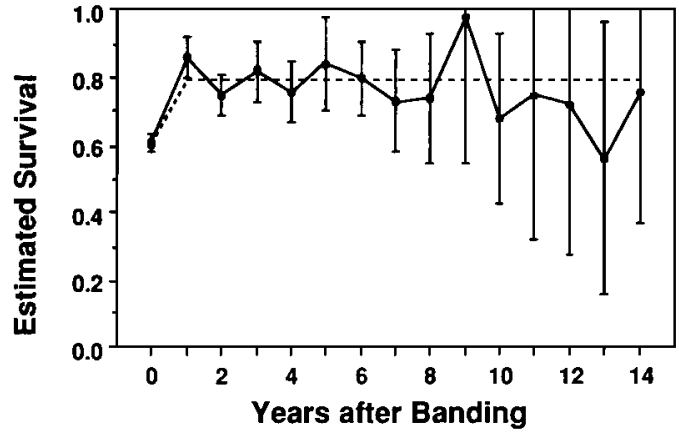

Fig. 3. Mean survival rates with approximate $95 \%$ confidence limits for female Lesser Snow Geese banded as adults at La Pérouse Bay, Manitoba, relative to number of years since original capture. Estimated from recapture information using program SURGE4 (Clobert et al. 1987). Estimates do not differ significantly from dashed line indicating no change after the first year.

breeding status in a fashion that may depend on age. Newly fledged geese have much lower survival rates than adults, as has been observed for most other species of birds. Several lines of evidence suggest that much of the mortality occurs before the geese leave the breeding areas, or on the first stage of migration. We show elsewhere that mean gosling survival is lowest in years when they hatch late, and in years when they grow more slowly, suggesting that the condition of the cohort has a strong effect on its mean survival (Francis et al. 1992). This effect is unlikely to be mediated by hunting, because we show in the same paper that gosling survival, at least at La Pérouse Bay, has declined significantly since 1970 despite a reduction in hunting pressure. Furthermore, a simple calculation indicates that hunting accounts for relatively little of the differential mortality. Assuming that about one-third of the geese killed by hunters are actually reported (Francis et al. 1992), estimated mortality from hunting is about $20 \%$ for newly fledged goslings from La Pérouse Bay (Table $2 ; 3 \times 6.7 \%$ ), while the mean annual mortality $(1-S)$ is about $58 \%$. Thus, about twothirds of gosling mortality is from causes other than hunting. In contrast, similar calculations suggest about $11 \%$ of adults are shot, while mean annual mortality is only $18 \%$, indicating that hunting accounts for more than one-half of adult mortality. Calculations from Cape Henrietta Maria also indicate that a high proportion of gosling mortality is not caused by hunters. Note, 
however, that even among adults, there is evidence for significant nonhunting mortality. The above estimates, as well as more rigorous models relating recovery rate and survival rate at La Pérouse Bay (Francis et al 1992), indicate that adults experience about $8 \%$ annual mortality unrelated to hunting. Unfortunately, the sampling errors for estimates of mortality in individual years are too unreliable to analyze the causes of this mortality in adults.

The apparent tendency for goslings from northern colonies to have lower survival relative to adults provides further evidence that conditions prior to migration influence gosling mortality. Harsher climates in the north or the greater length of the first segment of the migration could both adversely affect survival rates of goslings. The high variation among years in gosling survival would be expected if occasional severe storms caused substantial mortality, although the particularly low survival of goslings from Baffin Island in 1961 may have been exacerbated by adverse weather during banding, when young geese are particularly vulnerable (F. G. Cooch pers. comm.). The relatively small differences in survival between young and adults banded at migration stopover sites in Missouri and the Dakotas also indicates that much of the differential mortality occurs before the geese reach these sites.

Most mortality of young Barnacle Geese nesting on Svalbard and migrating to Britain also occurs on the breeding grounds or during migration (Owen and Black 1989). The precise cause of mortality for either of these goose species is not known, because corpses are very rarely found. Young Lesser Snow Geese in poor condition may have insufficient reserves to leave the breeding grounds, or at least the coastal marshes of Hudson Bay, before they are trapped by cold weather, although the food supply is unlikely to be completely frozen until October or November (E. G. Cooch pers. comm.). Such geese may also be very vulnerable to either predators or parasites. Alternatively, they may depart the coastal marshes, but have insufficient reserves to complete their first migration. Although the first segment of migration is much shorter for Lesser Snow Geese than for Barnacle Geese, at least for geese nesting at the more southerly colonies, and is largely over land rather than water, a Lesser Snow Goose that is forced to stop, for lack of nutrients, in the boreal forest may have little better chance of survival than a Barnacle Goose forced to stop at sea.
Yearlings continue to be slightly more vulnerable to hunters, and to have lower survival rates than adults, despite the fact that they do not breed. Yearlings may still lack experience with hunters, particularly because they are probably experiencing their first hunting season without the accompaniment of their parents. They may also be in poorer condition and, hence, more likely to suffer nonhunting mortality. Because the yearling survival estimates cover a one-year period, differential mortality in the following spring or summer, when some of the geese are breeding for the first time as two-year-olds, also would be included in the yearling survival estimates. Yearlings may also differ from breeding adults in the timing of their migration (Lumsden 1975), although it is not known whether these differences are sufficient to affect vulnerability to hunters. There were few differences in the distributions of recovery locations among any age classes from McConnell River in 1977 and 1978 (unpubl. data).

Owen and Black (1989) suggested that yearling Barnacle Geese actually had higher survival rates than breeding adults, in contrast to the Lesser Snow Geese. However, they did not provide estimates for older nonbreeders. Their estimates were based only on the first migration, and did not include any possible effects the following summer. Furthermore, the Barnacle Geese are not hunted, unlike the Lesser Snow Geese. Published estimates of yearling survival are not available for other species of geese, although survival of these birds is generally assumed to be the same as for adults (Samuel et al. 1990). For North American ducks, estimates from banding Mallards and other species of ducks at the end of the hunting season have not provided any evidence that yearlings differ in survival rates from older ducks (Nichols and Hines 1987).

The relatively low recovery rates of older nonbreeders indicate that they are less vulnerable to hunters than breeding geese. This could be partly due to differences in timing of migration, because nonbreeders tend to molt earlier, but we found few differences in the timing or distribution of recoveries between breeding and nonbreeding adults from McConnell River (unpubl. analyses). Probably the main cost to the breeding adults is the fact that they remain together with their goslings as a family group at least until the start of the spring migration (Prevett and MacInnis 1980). Anecdotal evi- 
dence from hunters, as well as the studies by Giroux and Bedard (1986) on Greater Snow Geese, indicate that young geese are particularly susceptible to being lured into decoys, and that their parents tend to follow them and may remain in the vicinity if the young are shot, thus increasing their vulnerability. Breeding adults could also suffer energetic costs from breeding that reduce their survival probabilities. Breeding female Barnacle Geese in a nonhunted population were significantly less likely to survive the autumn migration than nonbreeders, at least in some years (Owen and Black 1989). However, these costs would be expected to affect females more than males, and although there may be slight sexual differences in survival, there were no differences in direct recovery rates (Francis and Cooke 1992b). Also, for the geese from McConnell River in 1977 and 1978 , overall survival rates for breeders appear to be similar to, or actually slightly higher than nonbreeders (Table 3 ), despite the higher recovery rates. This apparent anomaly may indicate that nonbreeders were geese that were in worse condition initially (hence, the decision not to breed) and, thus, were more susceptible to nonhunting mortality. This reinforces the hypothesis that the main cost to breeders in terms of increased vulnerability is being accompanied by goslings, rather than an energetic cost.

Our data provide some indications that the costs of breeding depend upon the age or experience of a goose. Adults that had been caught in previous years and, hence, are presumably experienced breeders had significantly higher survival rates than newly captured geese, many of which were probably first-time breeders. Although this could represent a general loss of poor-quality individuals, the pattern is consistent with the hypothesis that first-time breeders suffer particularly high costs from breeding.

Apart from this possible cost to first-time breeders, we found little evidence for further changes in survival rate with age up to at least 12 years of age. Unfortunately, the power of our tests for older age classes is relatively low. Apart from the obvious decline in sample size for older age classes due to mortality, recovery rates have been declining, so that few recoveries are available in recent years when we have known-age old geese (Francis et al. 1992). In addition, recapture rates have declined because the colony has been expanding (Cooch et al. 1989). The result is that there is little infor- mation on which to base the survival estimates for older age classes, and they have increasingly wide confidence limits (Figs. 1-3). The age at which senescence might be expected to affect Lesser Snow Goose survival is not known. There is some evidence from the same population that geese beyond the age of eight years are less likely to recruit young (Ratcliffe et al. 1988). The slight trend for more direct recoveries of older birds may indicate that older birds are less able to avoid hunters. However, there were no indications of increased mortality rates for Barnacle Geese until at least 15 years of age (Owen 1984), and some seabirds such as Shorttailed Shearwaters do not appear to show increased mortality rates until they are 20 years old (Bradley et al. 1989). Newton (1989) suggested that senescence will occur at a fairly early age for small species with low annual survival rates, and may not be apparent until very old ages for larger species with high annual survival. Although the generalization was based upon only a few species (for which the statistics often were not very rigorous), it is quite possible that few Lesser Snow Geese from the La Pérouse Bay colony were old enough for senescence to be expected. Unfortunately, because of the difficulty of obtaining data on old birds, it will be many years before this hypothesis can be tested fully.

The extent to which hunting influences the observed patterns of age-dependent mortality in Lesser Snow Geese is not clear. Certainly, hunting is an important mortality factor for adult geese, although other factors, at least at present levels of hunting pressure, have a greater influence on gosling mortality. The differences between yearlings and older nonbreeders suggest that both experience and condition continue to improve with age for more than one year. Presumably, this would affect both hunting and nonhunting mortality, but too little is known about the latter to demonstrate the point. Data are not available to determine how breeding activity would affect mortality of adults in this population in the absence of hunting.

The marked influence of breeding status on both recovery and survival rates, and the persistence of age-specific mortality differences beyond the first year of life, apparently invalidate the models of Brownie et al. (1985) for estimating adult survival rates (Lakhani 1987). Fortunately, however, these models are fairly robust to these deviations, particularly when the differences between yearlings and adults are rel- 
atively small. Lakhani (1987) demonstrated that bias could be particularly large for estimating immature survival when yearling survival differs from that of adults, but we found through simulations that the bias is small for birds from La Pérouse Bay (Francis et al. 1992). Alternative models, such as those based on known-age birds advocated by Lakhani (1987), still could not differentiate breeders from nonbreeders. Furthermore, those models are critically dependent on the assumption that recovery probabilities are proportional to mortality, and do not change with age or time (Anderson et al. 1985). That assumption is strongly violated for Lesser Snow Geese, as well as most other species that have been examined (Burnham and Anderson 1979, Anderson et al. 1981).

We believe that, used cautiously, the models of Brownie et al. (1985), together with some of the variants used in this paper, remain the most appropriate means for testing hypotheses about survival rates from band-recovery data, and for obtaining estimates of mean survival. While we certainly do not advocate using models that clearly do not fit the data, we believe that in most cases when sample sizes are reasonably large, and the models are not rejected by the goodness-of-fit tests, the estimates are unlikely to be very biased. However, we caution that, at least for species with similar complexities of age-specific survival patterns to those of Lesser Snow Geese, the estimates are always likely to be slightly biased. Thus, it always will be necessary to consider how these biases could affect one's conclusions, particularly if the estimates are being used to model population dynamics.

\section{ACKNOWLEDGMENTS}

The bird-banding offices of the Canadian Wildlife Service and the U.S. Fish and Wildlife Service deserve credit for maintaining the data bases on all of the banding and recovery information, and providing us with the data on computer tape. We would like to thank the many field workers and banders at La Pérouse Bay and elsewhere who spent a great deal of time and effort banding Lesser Snow Geese, and gave us permission to analyse their data. Lesser Snow Goose research at La Pérouse Bay has been supported in part by the Natural Sciences and Engineering Research Council of Canada (NSERC), the Canadian Wildlife Service, the Manitoba Department of Renewable Resources, the Wildlife Management Institute, the Mississippi and Central Flyway Councils, Ducks Unlimited Canada, and Ducks Unlimited Incorporated. C.M.F. and M.H.R. were supported by fellowships from NSERC. C.M.F. also received an Urlla Carmi- chael scholarship and graduate awards from Queen's University, as well as grants from the Canadian Wildlife Service's university research support fund and the Chapman Fund of the American Museum of Natural History. J. D. Nichols, J. E. Hines, D. R. Anderson, J.-D. Lebreton, and G. C. White all kindly provided helpful advice, computer programs and/or manuals for data analysis. Please send reprint requests to Fred Cooke.

\section{LITERATURE CITED}

ANDERSON, D. R. 1975. Population ecology of the Mallard V. Temporal and geographic estimates of survival, recovery, and harvest rates. U.S. Fish Wildl. Serv, Resource Publ. 125.

Anderson, D. R., K. P. BurnhaM, And G. C. White. 1985. Problems in estimating age-specific survival rates from recovery data for birds ringed as young. J. Anim. Ecol. 54:89-98.

ANDERSON, D. R., A. P. WYWIALOWSKI, AND K. P. BurnHAM. 1981. Tests of the assumptions underlying life table methods for estimating parameters from cohort data. Ecology 62:1121-1124.

BLONDEl, J., AND R. PRADel. 1992. Is adult survival of the Blue Tit higher in a low fecundity insular population than in a high fecundity mainland one? Pages 131-143 in Population biology of passerine birds (J. Blondel, A. Gosler, J.-D. Lebreton, and R. McCleery, Eds.). Springer-Verlag, Berlin.

BotKIN, D. B., AND R. S. MILler. 1974. Mortality rates and survival of birds. Am. Nat. 108:181-192.

Bradley, I. S., R. D. WoOller, J. D. SKIRA, AND D. L. SERVENTY. 1989. Age-dependent survival of breeding Short-tailed Shearwaters Puffinus tenuirostris. J. Anim. Ecol. 58:175-188.

Brownie, C., D. R. ANDERSON, K. P. Burnham, AND D. S. RoBson. 1985. Statistical inference from band recovery data-A handbook, 2nd ed. U.S. Fish Wildl. Serv. Resource Publ. 156.

BUCKLAND, S. T. 1982. A mark-recapture survival analysis. J. Anim. Ecol. 51:833-847.

Burnham, K. P., AND D. R. ANDERSON. 1979. The composite dynamic method as evidence for agespecific waterfowl mortality. J. Wildl. Manage. 43:356-366.

Burnham, K. P., D. R. Anderson, G. C. White, C. Brownie, AND K. H. Pollock. 1987. Design and analysis methods for fish survival experiments based on release-recapture. Am. Fish. Soc. Monogr. 5.

CAVÉ, A. J. 1977. Pitfalls in the estimation of agedependent survival rates of birds from ringing and recovery data. Vogelwarte 29:160-171.

Clobert, J., J. D. Lebreton, AND D. Allaine. 1987. A general approach to survival rate estimation by recaptures or resightings of marked birds. Ardea 75:133-142.

Clobert, J., C. M. Perrins, R. H. McCleery, AND A. G. GosLER. 1988. Survival rate in the Great Tit 
Parus major in relation to sex, age, and immigration status. J. Anim. Ecol. 57:287-306.

COOCH, E. G., D. B. LANK, R. F. ROCKWELl, AND F. COOKE. 1989. Long-term decline in fecundity in a Snow Goose population: Evidence for density dependence? J. Anim. Ecol. 58:711-726.

CoOcH, F. G. 1961. Ecological aspects of the BlueSnow goose complex. Auk 78:72-89.

Cooke, F., C. D. Macinnes, And J. P. Prevetr. 1975. Gene flow between breeding populations of Lesser Snow Geese. Auk 92:493-510.

COULSON, J. C., AND R. D. WOOLLER. 1976. Differential survival rates among breeding Kittiwake Gulls Rissa tridactyla L. J. Anim. Ecol. 45:205-214.

EKMAN, J. 1984. Density-dependent seasonal mortality and population fluctuations of the temperate-zone Willow Tit (Parus montanus). J. Anim. Ecol. 53:119-134.

FINNEY, G. H., AND F. CoOKE. 1978. Reproductive habits in the Snow Goose: The influence of female age. Condor 80:147-158.

FraNCIS, C. M., AND F. COOKE. 1992a. Migration routes and recovery rates of Lesser Snow Geese from southwestern Hudson Bay. J. Wildl. Manage. 56: 279-286.

Francis, C. M., AND F. COOKE. 1992b. Sexual differences in survival and recovery rates of Lesser Snow Geese. J. Wildl. Manage. 56:287-296.

Francis, C. M., M. H. Richards, F. COOKe, and R. F. ROCKWELL. 1992. Long term changes in survival rates of Lesser Snow Geese. Ecology 73:1346-1362.

GIROUX, J.-F., AND J. BEDARD. 1986. Sex-specific hunting mortality of Greater Snow Geese along firing lines in Quebec. J. Wildl. Manage. 50:416-419.

HOPPER, R. M., H. D. FunK, AND D. R. ANDERSON. 1978. Age specificity in Mallards banded postseason in eastern Colorado. J. Wild1. Manage. 42: 263-270.

LACK, D. 1954. The natural regulation of animal numbers. Clarendon Press, Oxford.

LAKHANI, K. H. 1987. Efficient estimation of agespecific survival rates from ring recovery data of birds ringed as young, augmented by further field information. J. Anim. Ecol, 56:969-987.

LAKHANI, K. H., AND I. NEWTON. 1983. Estimating age-specific bird survival rates from ring recoveries-Can it be done? J. Anim. Ecol. 52:83-91.

Lebreton, J.-D., K. P. BurnhaM, J. CloberT, AND D. R. ANDERSON. 1992. Modeling survival and testing biological hypotheses using marked animals: A unified approach with case studies. Ecol. Monogr. 62:67-118.

Loery, G., K. H. Pollock, J. D. Nichols, AND J. E. HINES. 1987. Age-specificity of Black-capped Chickadee survival rates: Analysis of capture-recapture data. Ecology 68:1038-1044.

LUMSDEN, H. G. 1975. Differential migration in yearling and adult Lesser Snow Geese (Anser caerulescens). Bird-Banding 46:40-46.
Newton, I. 1989. Synthesis. Pages 441-469 in Lifetime reproduction in birds (I. Newton, Ed.). Academic Press, London.

Nichols, J. D., AND J. E. Hines. 1987. Population ecology of the Mallard VIII. Winter distribution patterns and survival rates of winter-banded Mallards. U.S. Fish Wildl. Serv. Resource Publ. 162.

OWEN, M. 1984. Dynamics and age structure of an increasing goose population - The Svalbard Barnacle Goose Branta leucopsis. Nor. Polarinst. Skr. 181:37-47.

OWEN, M., AND J. M. BLACK. 1989. Factors affecting the survival of Barnacle Geese on migration from the breeding grounds. J. Anim. Ecol. 58:603-617.

Pollock, K. H., J. D. Nichols, C. BRownie, AND J. E. HINES. 1990. Statistical inference for capturerecapture experiments. Wildl. Monogr. 107:1-97.

PrevetT, J. P., AND C. D. MacInnes. 1980. Family and other social groups in Snow Geese. Wildl. Monogr. 71:1-46.

PUGESEK, B. H. 1987. Age-specific survivorship in relation to clutch size and fledging success in California Gulls. Behav. Ecol. Sociobiol. 21:217221.

Pugesek, B. H., AND L. L. DIEM. 1990. The relationship between reproduction and survival in known-aged California Gulls. Ecology 71:811-817.

RAKESTRAW, J. L. 1981. Survival and recovery rates of Mallards banded postseason in South Carolina. J. Wildl. Manage. 45:1032-1036.

RATClifFe, L., R. F. RockWELl, AND F. COOKE. 1988 Recruitment and maternal age in Lesser Snow Geese Chen caerulescens caerulescens. J. Anim. Ecol. 57:553-563.

RiCKLEFS, R. E. 1973. Fecundity mortality and avian demography. Pages 366-434 in Breeding biology of birds (D. E. Farner, Ed.). National Academy of Sciences, Washington, D.C.

RockWEll, R. F., C. S. Findlay, AND F. COOKE. 1983. Life history studies of the Lesser Snow Goose (Anser caerulescens caerulescens) I. The influence of age and time on fecundity. Oecologia 56:318 322.

Samuel, M. D., D. H. Rusch, and S. Craven. 1990. Influence of neck bands on recovery and survival rates of Canada Geese. J. Wildl. Manage. 54:45 54.

SAS INSTITUTE. 1985. SAS user's guide: Statistics, version 5 ed. SAS Institute, Inc., Cary, North Carolina.

Sullivan, K. A. 1989. Predation and starvation: Agespecific mortality in juvenile juncos (Junco phaenotus). J. Anim. Ecol. 58:275-286.

SulzBACH, D. S. 1975. A study of the population dynamics of a nesting colony of the Lesser Snow Goose (Anser caerulescens caerulescens). M.Sc. thesis, Queen's Univ., Kingston. 